3. Грин, Н. В. Мультимедиа как средство медиаобразования при обучении английскому языку младших школьников/Н.В. Грин// В мире научных открытий. - 2013. - N 3. - С. 26-35.

4. Гнесюк, П.Б. Интерактивная доска: выбор, применение и рекомендации/П.Б. Гнесюк. - М.: «Литрес Самиздат», 2020. - 151 с.

5. Дьяконова, О. О. «Эдьютейнмент в обучении иностранным языкам» // Иностранные языки в школе 2013. - № 3. - С. 58-61.

6. Иловайская, Ю.В. Использование компьютерных программ в обучении иностранным языкам/Ю.В. Иловайская // Вестник МГУ. Сер. 19. Лингвистика и межкультурная коммуникация. - 2004. - № 3.C.17-22.

\title{
Булдакова Н.Б. \\ Факультативный курс по географии как основа дополнительного образования школьников
}

ФГБОУ ВО «Шадринский государственный педагогический университет» (Россия, Шадринск)

doi: 10.18411/lj-04-2021-137

\section{Аннотация}

В статье рассматриваются вопросы, посвящённые методике организации факультативного курса по географии. Автором обращается внимание на основные методы и приёмы проведения факультативных занятий. Приводятся примеры заданий, предлагаемых учащимся на факультативном курсе, посвящённом навыкам формирования умений работы с картой.

Ключевые слова: факультатив, география, географическая карта, учебновоспитательный процесс.

\section{Abstract}

The article deals with the issues related to the methodology of organizing an optional course in geography. The author draws attention to the main methods and techniques of conducting elective classes. Examples of tasks offered to students in an optional course devoted to the skills of forming skills of working with the map are given.

Keywords: elective course, geography, geographical map, educational process.

В настоящее время приоритетной задачей школы является не только всестороннее развитие личности учащихся, но и развитие тех способностей, которые у учащегося выражены наиболее хорошо. Необходимо удовлетворять потребности учащихся в тех знаниях, которые вызывают у них наибольший интерес и в будущем могут стать необходимыми для приобретения профессии и профессиональных навыков в определённой сфере. Одним из средств решения данной проблемы является организация в школе факультативных курсов. Они разрабатываются педагогами не только с целью углубления знаний обучающихся, но и для того чтобы сформировать у них умения самостоятельно расширять и пополнять свои знания, ориентироваться в обилии информации, поступающей из различных источников, а также для того, чтобы поддерживать интерес к учебе [1]. Всё вышеизложенное определяет актуальность нашего исследования.

В педагогической науке термины «факультативный курс» и «факультативные занятия» имеют разные толкования, с точки зрения многочисленных авторских подходов. Так, А. А Мельник определяя данную категорию, отмечает, что факультативный курс является предметом, изучаемым по личной инициативе учащихся общеобразовательных школ, либо иных учебных заведений [3]. С точки зрения Н. И. Запрудского, факультативный курс представляет собой самостоятельно выбранный учеником учебный предмет с целью углубленного его изучения и получения дополнительных знаний, в соответствии с интересами, потребностям и личными 
устремлениями [2]. Дополнительные факультативные занятия проводятся в соответствии с расписанием, утвержденным директором образовательной организации.

Проанализировав педагогический опыт, мы выявили, что факультативные курсы, направленные на формирование умений использования географических карт и других источников географической информации применяются в учебновоспитательном процессе достаточно широко. Такие педагоги, как В.А. Коптяева, Н.В. Хабарова, Е.В. Деменкова посвятили ряд работ методике работы с географической картой на уроках и предложили программы факультативных курсов по изучению географических карт. Однако такие курсы предлагаются, преимущественно, для старших школьников. На наш взгляд, изучение методики работы с картой целесообразно начинать в шестом классе, когда школьники знакомятся с основами географической науки [4].

Обратим внимание на общие требования к организации и проведению факультативного занятия. Обычно время проведения факультативного занятия не превышает 45 минут. Средняя наполняемость групп для проведения факультативных занятий должна составлять не менее пяти обучающихся в городских общеобразовательных школах, и не менее трех обучающихся в сельских школах. Организованы факультативные занятия в общеобразовательной школе, могут быть на базе только одного класса, (в зависимости от наполняемости группы), либо на базе всей параллели. Каждый факультативный курс состоит из серии факультативных занятий [3].

Рассмотрим особенности организации факультативного курса «Путешествие с географической картой». Факультативный курс предусмотрен для учащихся шестых классов. Основная цель данного курса - научить школьников пользоваться различными видами карт, получать из них максимум информации. Данный навык является необходимым для дальнейшего успешного изучения курса географии. Кроме того, указанные умения являются необходимыми в ряде жизненных ситуаций. Предлагаемый нами факультативный курс рассчитан на один учебный год, проводится раз в неделю. Курс включает теоретические и практические занятия. В процессе обучения школьников основам картографических знаний, необходимо использовать следующие основные методы: объяснительно-иллюстративный; практический; исследовательский. Объяснительно-иллюстративный метод предполагает объяснение теоретического материала с использованием наглядных пособий, которыми в данном случае будут служить географические, топографические карты и атласы. Практический метод является обязательным в процессе изучения этого географического факультативного курса, так как основная его цель - обучение практическим навыкам и приёмам работы с различными видами карт. Исследовательский метод используется после изучения большей части материала факультативного курса, когда школьники приступают к выполнению заданий творческого характера [4].

В процессе анализа и обобщения материалов научной и методической литературы, нами была разработана структура факультативного курса:

I. Tеоретические разделы факультативного курса:

1. История создания географической карты.

2. План местности. Приёмы составления плана местности.

3. Топографическая карта. Особенности чтения топографической карты.

4. Географическая карта. Виды географических карт.

5. Географические карты как инструмент исследовательской работы.

6. Использование географических карт в повседневной жизни.

7. Интерактивные карты.

II. Практические работы, предусмотренные факультативным курсом:

1. Методы и приёмы работы с географической картой.

2. Описание маршрута и территории по плану местности. 
3. Составление плана местности.

4. Чтение и анализ топографической карты.

5. Характеристика рельефа местности с помощью топографической карты.

6. Чтение и анализ общегеографической карты.

7. Чтение и анализ тематических карт.

8. Составление туристического маршрута с помощью географических карт.

9. Методы и приёмы работы с интерактивными картами. знаний.

III. Подведение итогов факультативного курса и обобщение полученных

Приведём примеры заданий для учащихся, предлагаемые им на практических занятиях.

Практическая работа: Чтение и анализ общегеографической карты.

Цель работы: научиться определять с помощью физической карты основные особенности местности.

Оборудование: физическая карта полушарий; физическая карта мира.

Задания:

1. Найти на карте Восточно - Европейскую равнину.

2. Указать преобладающие формы рельефа.

3. Указать наибольшие и наименьшие показатели высот рельефа.

4. Подумать и указать, благоприятен ли наблюдаемый на карте рельеф местности для жизни и хозяйственной деятельности человека: строительства транспортных дорог и зданий; разработки и использования сельскохозяйственных угодий.

5. Подсчитать количество гидрографических объектов на территории равнины. Перечислить крупнейшие реки и озёра. Сделать вывод на основе этих данных об обеспеченности территории пресной водой.

6. Изучив рельеф местности, подумайте, какое влияние такой тип рельефа оказывает на климат территории.

7. Какие крупнейшие населённые пункты расположены на территории Восточно - Европейской равнины.

Сделайте вывод о том, благоприятны ли наблюдаемые вами географические особенности местности для проживания людей и развития хозяйства.

Предлагаемые нами в практической работе задания способствуют развитию познавательного интереса к географической науке, так как школьники учатся видеть, какое количество информации можно получить с одной карты. Такие задания увлекают школьников, и они с интересом погружаются в учебную деятельность. Последовательность практических работ сформирована таким образом, что задания усложняются постепенно и не перегружают учащихся, не вызывают у них значительных затруднений, поэтому интерес к занятиям не угасает. В процессе выполнения практических заданий формируются и развиваются практические умения и навыки. Школьники, прошедшие такой факультативный курс, не будут испытывать сложности при дальнейшем изучении географической науки.

Таким образом, сделаем следующие выводы:

— основная цель факультативных курсов - расширение знаний учащихся в интересующей их сфере науки;

- факультативные курсы посещаются школьниками по желанию;

- факультативный курс «Географическая карта - источник информации» предназначен для школьников, начинающих изучать начальный курс географии, но испытывающих интерес к данной дисциплине; 
- основными методами и приёмами организации данного факультативного курса являются: объяснительно-иллюстративный; практический; исследовательский.

1. Душина, И. В. Методика и технология обучения географии : пособие для учителей и студентов / И. В. Душина. - Москва : ООО Издательство «Астрель», 2004. - 218 с. : ил. - Текст непосредственный;

2. Запрудский, Н. И. Организация факультативного обучения в 11-летней школе / Н. И. Запрудский. - Мн. : Зорны верасень, 2008. -215 с. - Текст непосредственный;

3. Румянцева, С. Е. Внеклассная работа и развитие личности учащихся / С. Е. Румянцева - Текст непосредственный // География в школе. - 2000. - № 6. - С. 55 - 57.;

4. Тишкевич, О. В. Формы, методы и средства проведения факультативного занятия / О.В. Тишкевич. - Текст электронный. - URL: https://nsportal.ru/blog/shkola/obshcheshkolnayatematika/all/2013/07/23/formy-metody-i-sredstva-provedeniya (дата обращения: 26.03.2021). - Режим доступа: для зарегистрир. пользователей.

\section{Вельдина Ю.В. \\ Преимущества и недостатки использования онлайн-технологий при обучении иностранному языку}

Пензенский государственный технологический университет (Россия, Пенза)

doi: 10.18411/lj-04-2021-138

\section{Аннотация}

Изучение иностранного языка с помощью онлайн-технологий приобретает всё большую популярность. В данной статье рассматриваются преимущества и недостатки использования в процессе обучения иностранному языку современных онлайнтехнологий, а также анализируются способы и результаты их применения.

Ключевые слова: онлайн-технология, иностранный язык, процесс обучения.

\section{Abstract}

Learning a foreign language with the help of online technologies is becoming increasingly popular. This article deals with the advantages and disadvantages of using modern online technologies in the foreign language educative process and analyses the ways and results of their use.

Keywords: online technology, foreign language, the educative process

Пандемия коронавируса (COVID-19) в корне изменила многие аспекты жизни. От нее пострадали все сферы государства, однако больше всего потерь понесли система здравоохранения и экономика, и мир сейчас стоит на грани глобального экономического кризиса. Необходимость социального дистанцирования и минимальных контактов для предотвращения распространения инфекции изменили способы коммуникации и взаимодействия между людьми. Альтернативные средства коммуникации, в частности Интернет, заменил собой традиционные методы. Интернетуслуги, например, онлайн-конференции через платформы Zoom или Skype, a также онлайн-обучение через платформы Moodle стали неотъемлимой частью делового и учебного процесса.

В связи с этим возник вопрос о том, каким же образом система образования в целом, и система высшего образования, в частности, будет адаптироваться с поставленной задачей, а именно, обучением студентов. В настоящее время большинство вузов переведено полностью на дистанционный формат обучения, либо процесс строиться на смешанном формате (часть занятий, преимущество лекции, 